\title{
Citotoxicidade in vitro de nanopartículas de fosfato tricálcico- $\beta$ sintetizado via reação em estado sólido
}

\author{
In vitro cytotoxicity of $\beta$-tricalcium phosphate \\ nanoparticles synthesized via solid \\ state reaction
}

\author{
${ }^{1}$ Laboratório de Biomateriais - Biomat - Pós-Graduação em Engenharia e Ciência de Materiais - Universidade Federal do \\ Ceará PGECM/UFC, CEP: 60440554, Fortaleza, Ceará, Brasil. \\ e-mail: suelinhasilva@gmail.com \\ ${ }^{2}$ Laboratório de Biomateriais - Biomat - PPGECM/UFC CEP: 60440554, Fortaleza, Ceará, Brasil. \\ e-mail: emilio@ufc.br, joelanecarvalhot@hotmail.com,svalbuquerque@gmail.com, eder235@hotmail.com.
}

\section{RESUMO}

O Fosfato Tricálcico- $\beta$ (TCP- $\beta$ ) é um material sintético que apresenta composição química similar à do tecido ósseo, sendo, por essa razão, frequentemente empregado como biomaterial. Nesta pesquisa, TCP- $\beta$ foi sintetizado por reação via estado sólido e caracterizado por Difração de Raios X (DRX), Espectroscopia de Infravermelho (IV), Microscopia Eletrônica de Varredura (MEV) e Espectroscopia de Raios X por Dispersão de Energia (EDX). A área superficial e a distribuição do tamanho de partículas foram determinadas pelo método BET (Brunauer-Emmet-Teller). Também se realizou teste de citotoxicidade segundo as normas ISO 10993-5 e ISO 10993-12. As técnicas de DRX e IV permitiram confirmar a formação da fase fosfato tricálcico- $\beta$, mediante seus padrões de difração e dos grupos funcionais característicos, respectivamente. Através do BET, constatou-se o caráter nanométrico das partículas sintetizadas. O MEV permitiu comparar a evolução da morfologia microestrutural, antes e após o tratamento térmico. Com os resultados de EDX, calculou-se a razão molar entre cálcio e fósforo, parâmetro usualmente empregado para identificação das diferentes fases de apatitas. No ensaio de citotoxicidade, as amostras não apresentaram alterações celulares (morfologia) e nem inibição do crescimento celular, indicando que, nas condições in vitro, o material não é tóxico. Todas essas caracterizações sugerem que o fosfato tricálcico- $\beta$ obtido pode ser potencialmente utilizado para aplicações biomédicas.

Palavras-chave: Biomateriais, Fosfato Tricálcico- $\beta$, Citotoxicidade.

\section{ABSTRACT}

The $\beta$-tricalcium phosphate ( $\beta$-TCP) is a synthetic material that present similar chemical composition to bone tissue and is frequently used as biomaterial. In this research, $\beta$-TCP was synthesized by solid state reaction and characterized by X-ray Diffraction (XRD), Infrared (IR) Spectroscopy, Scanning Electron Microscopy (SEM) and Energy Dispersive X-ray Spectroscopy (EDX). The surface area and particle size distribution were determined by BET method (Brunauer-Emmet-Teller). A cytotoxicity test was performed according to ISO 10993-5 and ISO 10993-12. Diffraction patterns (XRD) and characteristic functional groups (IR) of material allowed to confirm the formation of the $\beta$-TCP phase. BET leaded to verification of the nanometric character of the synthesized particles. SEM allowed to compare the evolution of the microstructural morphology before and after heat treatment. Molar ratio of calcium phosphate nanoparticles, usually used to identify the different phases of apatites, was calculated by EDX. In the cytotoxicity assay, the samples showed no cellular morphological changes or inhibition of cell growth, indicating that the material is nontoxic. All these characterizations suggest that the obtained $\beta$-tricalcium phosphate may be potentially used for biomedical applications. 
Keywords: Biomaterials, $\beta$-Tricalcium Phosphate, Cytotoxicity.

\section{INTRODUÇÃO}

Biomateriais são materiais, de origem natural ou sintética, utilizados para o desenvolvimento de dispositivos que entram em contato com sistemas biológicos, visando reparar perdas teciduais ou restaurar funções comprometidas por traumatismos e processos degenerativos. Apesar dos efeitos benéficos desses materiais, é comum que eles próprios acabem provocando, em maior ou menor grau, alguma resposta imunológica adversa do receptor [1]. Nesse contexto, os materiais biológicos, principalmente enxertos de origem autógena (do mesmo indivíduo), são os que apresentam maior potencial para uso como biomateriais graças à combinação favorável de propriedades (osteogênese, osteocondução e osteoindução) e ao risco mínimo de rejeição. Entretanto, sua aplicação limita-se à adequação de certos fatores como localização e tamanho do defeito. Com a finalidade de superar tais limitações, diversos materiais sintéticos têm sido utilizados para a substituição ou restauração de partes danificadas do tecido ósseo, permitindo, em muitos casos, a redução ou supressão do uso de materiais de origem biológica [2].

De um modo geral, os biomateriais devem ser biofuncionais e biocompatíveis. De acordo com a ISO 10993-5 [3], o ensaio de citotoxicidade in vitro constitui um teste inicial que permite avaliar a biocompatibilidade de qualquer material para uso como biomaterial. Através desse resultado preliminar, é possível observar a interação entre o material e o corpo biológico, de forma rápida e eficaz [4, 5]. Os estudos de citotoxicidade, que envolvem testes com culturas celulares, caracterizam-se por serem métodos rápidos, sensíveis, reprodutíveis e de baixo custo [6,7,8]. Por isso, o cultivo de células in vitro constitui valiosa técnica para se estudar os mecanismos pelos quais biomateriais podem ou não produzir reações adversas em nível celular [9].

No presente trabalho, realizou-se teste de citotoxicidade para o fosfato tricálcico- $\beta$ sintetizado via reação em estado sólido, empregando-se MTT como corante e células fibroblastos murinos (linhagem Clone NCTC L929), segundo as normas ISO 10993-5 e ISO 10993-12.

\section{MATERIAIS E MÉTODOS}

\subsection{Materiais}

Os precursores empregados para a síntese de TCP- $\beta$ foram hidróxido de cálcio $\left[\mathrm{Ca}(\mathrm{OH})_{2} 96 \%\right.$ - FLUKA®] e hidrogeno fosfato de cálcio [CaHPO $498 \%$ - DINÂMICA®].

\subsection{Métodos}

\subsubsection{Síntese de Fosfato Tricálcico- $\beta$}

Para a síntese do TCP- $\beta$, os reagentes foram pesados segundo a estequiometria da Equação 1.

$$
\mathrm{Ca}(\mathrm{OH})_{2}+2 \mathrm{CaHPO}_{4} \leftrightarrows \mathrm{Ca}_{3}\left(\mathrm{PO}_{4}\right)_{2}+2 \mathrm{H}_{2} \mathrm{O}
$$

Em um almofariz de ágata, hidróxido de cálcio e hidrogeno fosfato de cálcio foram homogeneizados e, em seguida, calcinados em forno mufla a $1000{ }^{\circ} \mathrm{C}$ com taxa de aquecimento de $5{ }^{\circ} \mathrm{C} /$ min durante 1 hora, tempo suficiente para a ocorrência da reação. Após caracterizações preliminares e confirmação da fase desejada, os precursores foram misturados, prensados e calcinados a fim de se obter corpos de prova para caracterizações subsequentes. Foram produzidos corpos de prova cilíndricos de $6 \mathrm{~mm}$ de altura e $12 \mathrm{~mm}$ de diâmetro, mediante aplicação de uma força de $1 \mathrm{~T}$ (tonelada) durante vinte segundos, em prensa uniaxial.

\subsubsection{Difração de Raios X (DRX)}

A análise de difração de raios $\mathrm{X}$ foi realizada em difratômetro da marca Panalytical modelo XPERT Pro $M P D$, empregando-se tubo de cobalto. O intervalo angular (em 20) utilizado foi de 20 a $60^{\circ}$ com uma velocidade de varredura de $0,5^{\circ} / \mathrm{min}$.

Os difratogramas obtidos foram comparados a padrões encontrados na literatura através do banco de dados JCPDS (Joint Committee on Powder Diffraction Standards), com auxílio do programa X'Pert HighScore Plus. A amostra calcinada passou por um processo chamado de refinamento de estrutura Rietveld [10] utilizando-se o programa DBWSTools [11]. 


\subsubsection{Espectroscopia de Infravermelho (IV)}

Para a identificação dos grupamentos funcionais presentes no pó sintetizado, empregou-se espectrômetro ABB, modelo FTLA 2000. O pó foi misturado em $\mathrm{KBr}$, prensado na forma de pastilha e analisado por técnica de transmitância, adotando intervalos de $4000-400 \mathrm{~cm}^{-1}$.

\subsubsection{Determinação do Tamanho Médio de Partículas (BET)}

A determinação da área superficial específica do pó sintetizado foi realizada pelo método de Brunauer, Emmet e Teller (BET) que consiste na adsorção física de um gás pela amostra. Empregou-se o equipamento Quantachrome Instruments modelo Autosorb-1C e gás $\mathrm{N}_{2}$ como adsorvedor.

Com o valor de área obtido, estimou-se o tamanho médio das partículas utilizando a Equação 2.

$\mathrm{D}_{\mathrm{BET}}=\frac{6}{\rho_{\mathrm{T}} \cdot \mathbf{A E} \mathrm{BET}}$

Onde:

$\mathrm{D}_{\mathrm{BET}}$ - diâmetro médio das partículas (nm);

$\rho_{\mathrm{T}}$ - densidade teórica do material;

$\mathrm{AE}_{\mathrm{BET}}$ - área superficial $\left(\mathrm{m}^{2} / \mathrm{g}\right)$.

\subsubsection{Microscopia Eletrônica de Varredura (MEV) e Espectroscopia de Raios X por Dispersão de Energia (EDX)}

A análise foi realizada em um microscópio de varredura FEG Quanta 450 ambiental com EDX/EBSD. A amostra foi fixada em um suporte com fita de carbono dupla-face e recoberta com carbono, utilizando-se um sistema de deposição a vácuo Bal-Tec. A microscopia permitiu obter dados sobre a morfologia e tamanho das partículas formadas. A espectroscopia teve como finalidade quantificar a relação molar $\mathrm{Ca} / \mathrm{P}$ após o processo de síntese.

Para determinação do tamanho das partículas dos corpos de prova calcinados, as micrografias foram analisadas através do ImajeJ, programa de domínio público desenvolvido pelo National Institute of Health, NIH, Estados Unidos. Realizaram-se aproximadamente 100 medições considerando-se partículas aleatórias da imagem.

\subsubsection{Ensaio de Citotoxicidade}

A análise de citotoxicidade in vitro do pó sintetizado foi realizada de acordo com a norma ISO 10993-5 [3]. A amostra de referência Zdec (dietilditiocarbamato de zinco) e a sintetizada foram extraídas em meio de cultura durante 24 horas a $37{ }^{\circ} \mathrm{C}$ com $5 \%$ de $\mathrm{CO}_{2}$, conforme a norma ISO 10993-12 [12]. O extrato foi testado a uma concentração máxima de $100 \%$ e as demais em diluição seriada de $50 \% ; 25 \% ; 12,50 \% ; 6,25 \%$; $3,12 \%$ e $1,56 \%$.

As células (linhagem NCTC clone L929) foram semeadas em placas de 96 poços na densidade de $10^{4}$ células $/ 100 \mu \mathrm{L}$ e cultivadas em meio de cultura MEM (meio mínimo de Eagle) suplementado com $10 \%$ de soro e $1 \%$ de solução composta dos antibióticos penicilina $(100 \mathrm{U} / \mathrm{mL})$ e estreptomicina $(100 \mu \mathrm{g} / \mathrm{mL})$. As placas de 96 poços foram incubadas $\left(37^{\circ} \mathrm{C}\right)$ em estufa umidificada em atmosfera de $5 \%$ de $\mathrm{CO}_{2}$ por 24 horas, a fim de permitir a sedimentação e a adesão celular. Após esse período, a amostra produzida e a substância de referência foram adicionadas às culturas celulares.

Após exposição de 24 horas, o meio foi retirado e adicionado a cada poço - $50 \mu \mathrm{L}$ de solução com o corante MTT [brometo de 3 - (4,5 - dimetil - 2 - tiazolil) - 2,5 - difenil - $2 \mathrm{H}$ - tetrazólio] (1 mg/mL). As placas foram incubadas $\left(37^{\circ} \mathrm{C}\right)$ em estufa umidificada em atmosfera de $5 \%$ de $\mathrm{CO}_{2}$ por 2 horas. Logo após, a solução de MTT foi removida e o precipitado de sal reduzido (Formazan) ressuspendido em $100 \mu \mathrm{L}$ de álcool isopropílico. Para a quantificação do Formazan, as absorbâncias de cada poço foram obtidas com o auxílio do espectrofotômetro, no comprimento de onda de $570 \mathrm{~nm}$.

Os cálculos de viabilidade celular foram feitos a partir da Equação 3 (norma ISO 10993-5).

Viab. $\%=\frac{100 \times O D_{570 e}}{O D_{570 b}}$

Onde:

Viab. \% - viabilidade em porcentagem; 


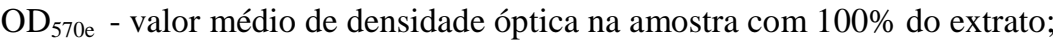

$\mathrm{OD}_{570 \mathrm{~b}}$ - valor médio de densidade óptica medida no poço de controle com as células NCTC Clone L929.

\section{RESULTADOS E DISCUSSÃO}

\subsection{Difração de Raios X (DRX)}

Antes do processo de síntese, os precursores químicos foram misturados, homogeneizados e caracterizados por difração de raios X, a fim de se verificar a pureza dos reagentes e ausência de contaminantes (Figura 1).

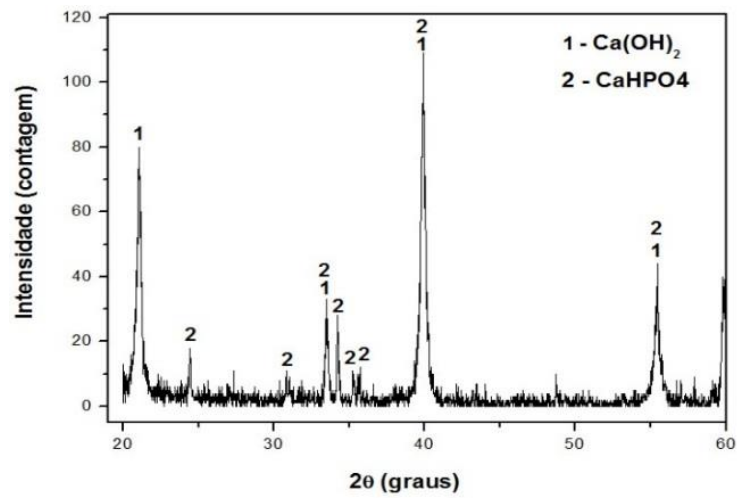

Figura 1: Difração de raios X da amostra antes da calcinação.

Uma vez constatada a pureza desses compostos, procedeu-se a síntese, de acordo com a Equação 1, em estado sólido. Em geral, os processos usuais de precipitação química, para síntese de hidroxiapatita e do fosfato tricálcico- $\beta$, envolvem a preparação de uma solução homogênea de sais, contendo um dos íons de interesse, e a sua mistura com um agente precipitante (contendo o outro íon), resultando em um precipitado que é separado por filtração. Contudo, nem sempre esse precipitado é o material desejado, mas um intermediário que somente se converte ao produto esperado, após tratamento térmico [13,14]. Na rota de precipitação química, é preciso ainda um controle rigoroso dos parâmetros do processo (temperatura, $\mathrm{pH}$, tempo de reação etc), de tal modo que qualquer alteração pode levar a modificações da composição do produto final, revelando fases de outros fosfatos, principalmente para o TCP- $\beta$ [15].

Seguindo uma análise comparativa, o mecanismo de síntese adotado neste trabalho apresentou vantagens em relação à técnica anteriormente descrita. Evidentemente, foram realizados alguns testes até a combinação ideal entre quantidades de reagentes e parâmetros do processo (tempo, temperatura e taxa de aquecimento), mas, uma vez determinadas as condições adequadas, não houve mais necessidade de controle daqueles parâmetros. Além disso, obteve-se diretamente o produto desejado (TCP- $\beta$ ), sem a presença de fases concomitantes, conforme pode ser observado no difratograma da Figura 2.

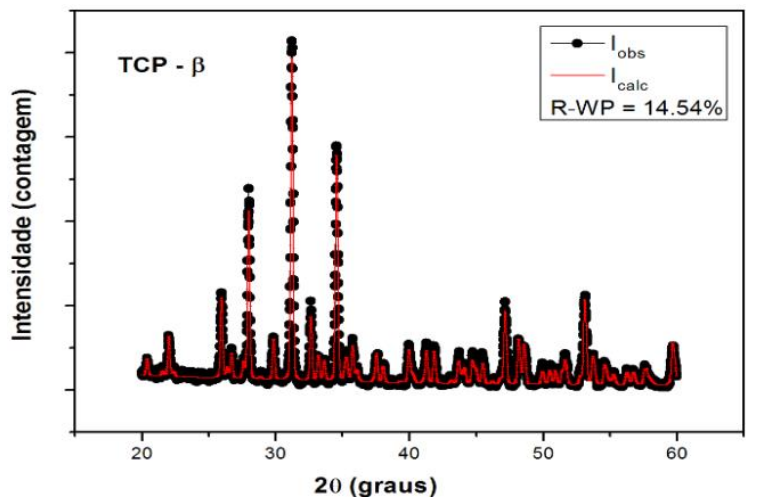

Figura 2: Difração de raios $\mathrm{X}$ da amostra calcinada a $1000{ }^{\circ} \mathrm{C}$. 
A Figura 2 apresenta o padrão de difração observado $\left(\mathrm{I}_{\mathrm{obs}}\right)$, o padrão calculado $\left(\mathrm{I}_{\text {calc }}\right)$ e o parâmetro RWP determinado após refinamento Rietveld. Nesse tipo de refinamento, há alguns dados quantitativos que refletem seu progresso. Destes, o parâmetro R-WP é o fator estatisticamente mais significativo, tendo em vista que sua expressão analítica envolve o método dos mínimos quadrados entre as intensidades calculadas e a intensidades observadas [16]. Os resultados de R-WP são considerados bons na faixa de 2 a 10\%, enquanto os valores típicos variam entre 10 e $20 \%$ [16]. Neste estudo, o valor obtido (14,54\%) mostrou-se satisfatório.

Outros autores também utilizaram a caracterização por DRX para comprovar a obtenção do fosfato tricálcico. OPRITA et al. [17] utilizando di-hidrogenofosfato de amônia $\left(\mathrm{NH}_{4} \mathrm{H}_{2} \mathrm{PO}_{4}\right)$ e carbonato de cálcio $\left(\mathrm{CaCO}_{3}\right)$ com razão molar 2:3 e temperatura de calcinação de $1100{ }^{\circ} \mathrm{C}$, obtiveram TCP- $\beta$ por decomposição, sendo o material posteriormente caracterizado por DRX. ZOU et al. [18], por sua vez, sintetizaram TCP- $\beta$ por precipitação em solução aquosa, seguida de calcinação a $900{ }^{\circ} \mathrm{C}$, durante 3 horas. A análise DRX revelou a presença da fase cristalina TCP- $\beta$ segundo a ficha padrão (JCPDS 70-2065). Neste estudo, os picos característicos do TCP- $\beta$ também foram identificados de acordo com a ficha JCPDS 70-2065, com auxílio do programa X'Pert HighScore Plus.

O padrão de difração permitiu ainda tecer algumas considerações com relação à cristalinidade do material sintetizado. A cristalinidade pode ser avaliada qualitativamente pelos picos de difração. Amostras, como a caracterizada, que apresentam picos acentuados e agudos, têm maior cristalinidade, ao passo que amostras, contendo picos de difração largos e de baixa intensidade, são consideradas pouco cristalinas [19, 20]. Efetivamente, o grau de cristalinidade foi calculado, aplicando-se a técnica descrita no trabalho de LANDI et al. [21], e resultou no valor aproximado de 74,3\%. Como a amostra não chegou a ser sinterizada, o valor calculado está de acordo com o esperado.

\subsection{Espectroscopia de Infravermelho (IV)}

A análise de espectroscopia de infravermelho foi realizada com o objetivo de complementar as informações obtidas pela técnica de DRX. A Figura 3 apresenta, na região de $4000-400 \mathrm{~cm}^{-1}$, as bandas mais significativas referentes ao fosfato de cálcio sintetizado.

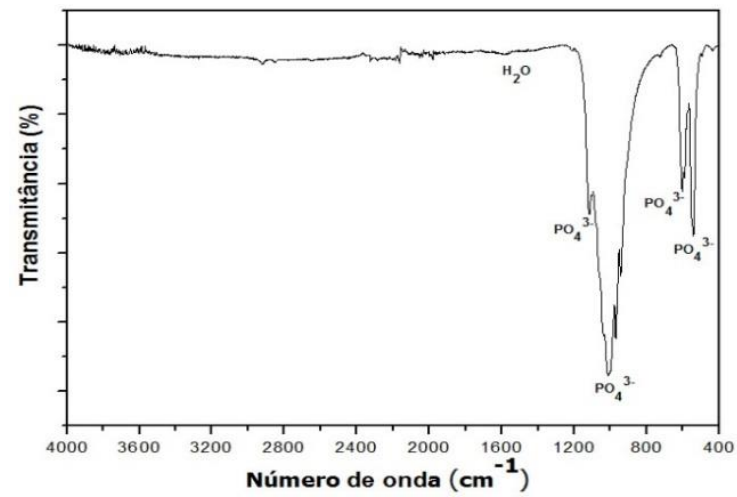

Figura 3: Infravermelho da amostra calcinada a $1000{ }^{\circ} \mathrm{C}$.

O espectro é semelhante ao descrito na literatura para os fosfatos de cálcio. Segundo REYNAUD et al. [22], as bandas 460, $550-600,960,1020-1120 \mathrm{~cm}^{-1}$ são características dos grupos fosfato e correspondem à deformação assimétrica do O-P-O em $\mathrm{PO}_{4}^{-2}$. Observa-se a presença do pico $723 \mathrm{~cm}^{-1}$, característico do modo simétrico $v(\mathrm{P}-\mathrm{O}-\mathrm{P})$ e atribuído a harmônicos de deformação. A visualização das bandas vibracionais próximas às de $960-1120 \mathrm{~cm}^{-1}$ correspondem ao estiramento assimétrico do P-0 no grupo $\mathrm{PO}_{3}^{-2}[23,24]$.

Não foram encontradas bandas em 630 e $3540 \mathrm{~cm}^{-1}$, relacionadas às hidroxilas $(\mathrm{OH})$, que poderiam indicar a presença de hidroxiapatita. Também não se identificaram bandas em $460,740 \mathrm{~cm}^{-1} \mathrm{e} 600 \mathrm{~cm}^{-1}$, características do TCP- $\alpha$. Por outro lado, a banda de $900-1200 \mathrm{~cm}^{-1}$ é representativa do TCP- $\beta$.

No mais, a banda mais larga na região entre 3700 e $2600 \mathrm{~cm}^{-1}$, apesar de pouco perceptível, está associada à água fisicamente adsorvida. 


\subsection{Determinação do Tamanho Médio de Partículas (BET)}

A área superficial específica calculada, via análise BET, foi de $24,17 \mathrm{~m}^{2} / \mathrm{g}$. Este dado, quando inserido na Equação 2, forneceu o valor aproximado de $81 \mathrm{~nm}$ para o diâmetro das partículas. Segundo a literatura, materiais que apresentam diamêtro entre 1 e 100 nanômetros são classificadas como nanométricos [25, 26, 27, 28, 29]. É relevante salientar que diferentes métodos de síntese vêm sendo utilizados na produção de pós de fosfatos de cálcio, na tentativa de se obter partículas com tamanhos nanométricos e área superficial elevada, já que estas características são importantes para os estudos de reparação e reconstituição do tecido ósseo.

\subsection{Microscopia Eletrônica de Varredura e Espectroscopia de Raios X por Dispersão de Energia (MEV- EDX)}

As Figuras 4, 5 e 6 apresentam as imagens obtidas por MEV das amostras antes e após a síntese do TCP- $\beta$. $\mathrm{Na}$ Figura 4, representativa dos pós não calcinados, observam-se apenas grandes aglomerados.

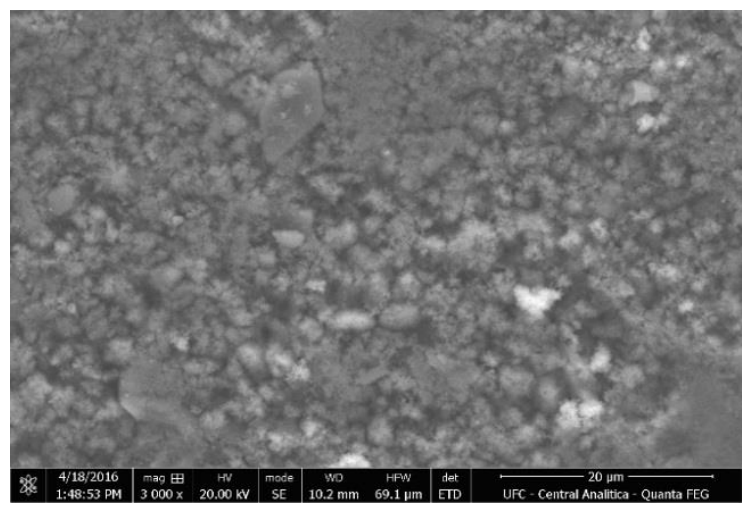

Figura 4: Imagem da amostra antes da calcinação.

Ao se comparar a Figura 4 com a Figura 5, abaixo, evidencia-se uma mudança radical de morfologia, após o tratamento térmico, com a formação de partículas globulares ou esféricas. Apesar de não ocorrer sinterização, é possível notar a formação de pescoços entre as partículas.

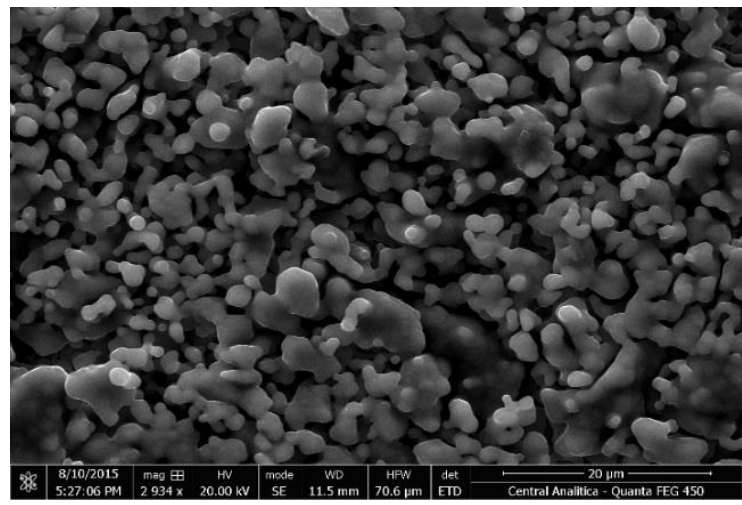

Figura 5: Morfologia da amostra de TCP- $\beta$ com aumento de 2934x.

Constatou-se que a calcinação, realizada a $1000{ }^{\circ} \mathrm{C}$, promoveu o crescimento das partículas levando a uma densificação aparente do material. Através de medições realizadas a partir do programa ImageJ, obtevese diâmetro médio de $3,52 \mu \mathrm{m}$.

Neste ponto, é interessante destacar a diferença entre os métodos adotados para determinação do tamanho de partículas. A análise de BET é feita para amostras pulverizadas, enquanto MEV faz uso de peças moldadas. Por isso, as amostras calcinadas, caracterizadas na forma de pós (BET) e na forma de corpos de prova prensados (MEV), forneceram resultados distintos para tamanho das partículas. Nas amostras avaliadas por MEV, embora não tenha ocorrido a sinterização propriamente dita, observaram-se fenômenos associados à mesma, como a formação de pescoços, o crescimento de grão e a densificação, razões pelas quais, ao se 
analisar as micrografias, encontraram-se apenas estruturas micrométricas, diferente das nanopartículas identificadas no BET. Esse caráter micrométrico das partículas também é percebido visualmente, principalmente, quando se considera o maior aumento (Figura 6). Vale ainda salientar que, devido à sua área superficial elevada, amostras de apatitas constituídas de pós nanométricos densificam mais facilmente, mesmo quando aquecidas a baixas temperaturas.

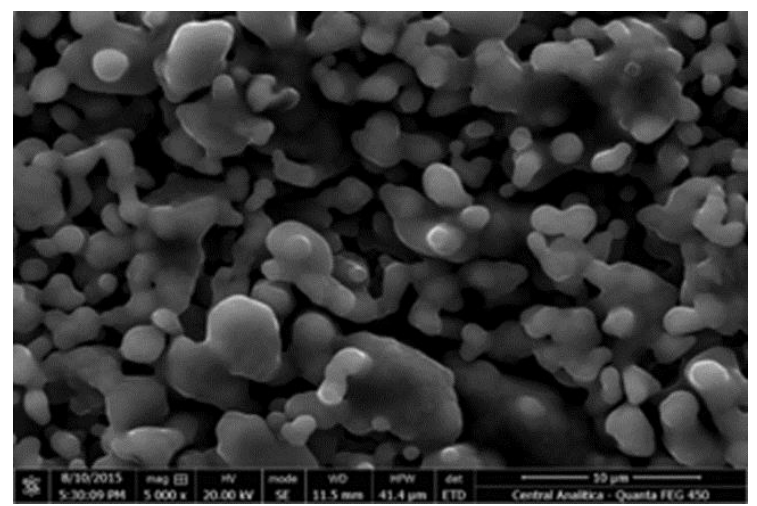

Figura 6: Morfologia da amostra de TCP- $\beta$ com aumento de 5.000x.

A composição elementar das amostras calcinadas de TCP- $\beta$ foi determinada por meio de EDS (Figura 7), confirmando, mais uma vez, a presença dos elementos característicos das apatitas.

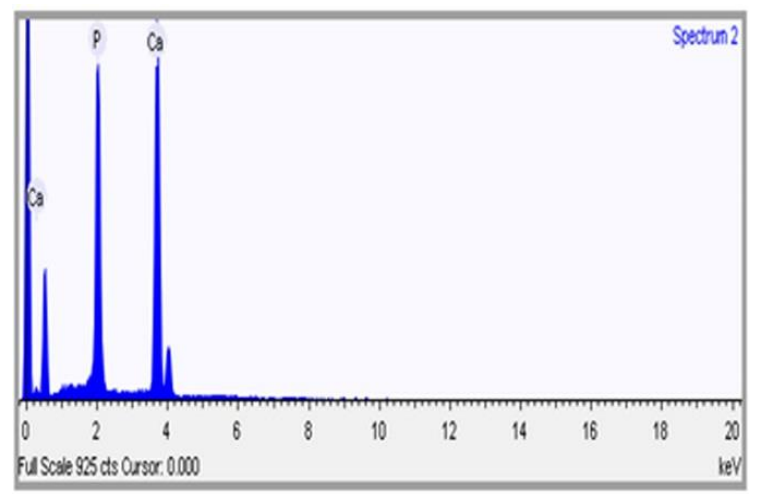

Figura 7: Mapeamento dos grupos funcionais do TCP- $\beta$.

A Tabela 1 apresenta a análise quantitativa feita por MEV/EDX.

Tabela 1: Análise quantitativa da amostra de TCP- $\beta$.

\begin{tabular}{l|l|l}
\hline ELEMENTO & PESO (\%) & ATÔMICO (\%) \\
\hline Fósforo & 19,776 & 15,256 \\
\hline Cálcio & 39,084 & 23,301 \\
\hline Oxigênio & 41,139 & 61,442 \\
\hline
\end{tabular}

A razão molar de $\mathrm{Ca} / \mathrm{P}$, calculada através do percentual atômico (Tabela 1), foi de 1,52. Segundo a literatura, o TCP- $\beta$ apresenta razão molar de 1,50 [30, 31, 32, 33, 34], o que corrobora a formação da amostra desejada.

\subsection{Avaliação do Potencial Citotóxico}

De acordo com o Órgão Internacional de Padronização (International Standard Organization), ISO 10993, o ensaio de citotoxicidade in vitro é o primeiro teste para avaliar a biocompatibilidade de qualquer material para uso em dispositivos biomédicos. Somente depois de comprovada a sua não toxicidade, é que o estudo da 
biocompatibilidade do produto pode ter continuidade, realizando-se os ensaios necessários em animais de laboratório [35].

Os testes de citotoxicidade consistem em colocar o material direta ou indiretamente em contato com uma cultura de células de mamíferos, verificando-se as alterações celulares por diferentes mecanismos, como a incorporação de corantes vitais ou a inibição da formação de colônias celulares. O parâmetro mais utilizado para avaliar a toxicidade é a viabilidade celular, que pode ser evidenciada com auxílio dos corantes vitais já mencionados (a intensidade de cor da cultura permite distinguir entre células vivas e danificadas ou mortas) [36].

A citotoxicidade pode ser determinada através de avaliação qualitativa ou quantitativa. A avaliação qualitativa é realizada pelo exame microscópico das células para verificação de mudanças na morfologia geral, vacuolização, destacamento, lise celular ou de membrana e o resultado é relatado como: atóxica, leve, moderada ou severa citotoxicidade. Na avaliação quantitativa, é realizada medida de morte celular, proliferação celular ou formação de colônias celulares. O número de células, quantidade de proteínas, liberação de enzimas, liberação ou redução de corante vital ou outro parâmetro de medida pode ser quantificado por meios objetivos.

Para mensurar o potencial citotóxico da amostra em estudo, realizaram-se análises qualitativa e quantitativa de acordo com a norma ISO 10993-5. Como controle positivo da análise, empregou-se a amostra de referência Zdec (dietilditiocarbamato de zinco). O poço de controle com as células (NCTC Clone L929), em meio de cultura MEM, foi usado como controle negativo. A amostra escolhida para controle negativo não pode causar prejuízo às células (atóxica), ao passo que o controle positivo deve ser um material que apresente nocividade celular (tóxico) [36].

$\mathrm{Na}$ análise qualitativa, a amostra de fosfato não apresentou alterações celulares morfológicas, como também não inibiu o crescimento celular, conforme as Figuras 8 e 9.

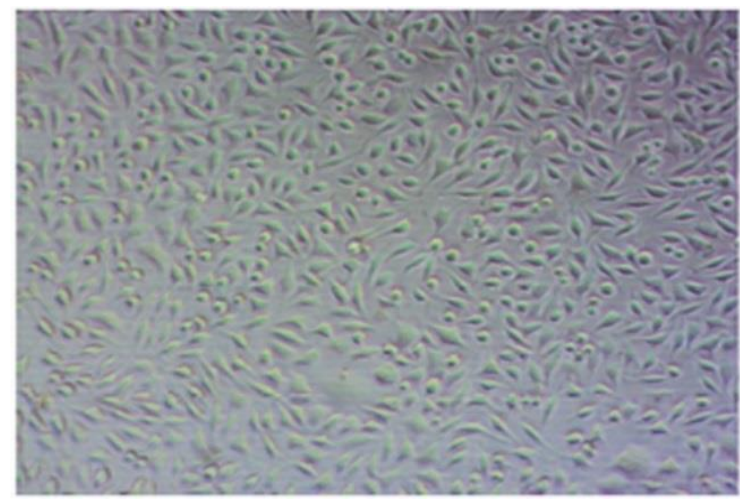

Figura 8: Imagem representativa do poço de controle com as células (NCTC Clone L929), em meio de cultura MEM. Aumento de 10x.

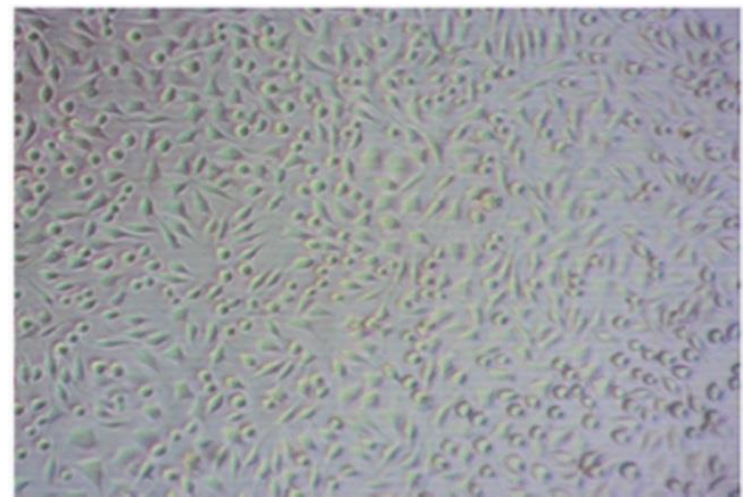

Figura 9: Imagem representativa do poço de células (NCTC clone L929) incubadas com a substância de TCP- $\beta$. Aumento de 10x. 
De acordo com os resultados, as amostras não apresentaram nenhuma reatividade nem redução do crescimento celular, sendo classificadas como grau 0 [3]. O resultado foi considerado promissor, pois as amostras apresentaram comportamento semelhante ao poço de controle (Figura 8) em todas as concentrações testadas.

Para a amostra de referência Zdec, observou-se completa destruição da camada de células, com inibição do crescimento celular, conforme comparação entre as Figuras 10 e 11. A amostra foi classificada como grau 4, por apresentar reatividade severa.

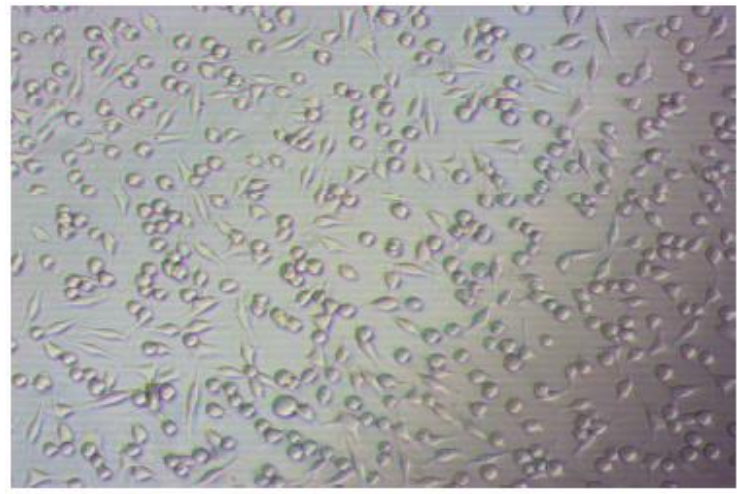

Figura 10: Imagem representativa do poço de controle com as células (NCTC Clone L929) em meio de cultura MEM.

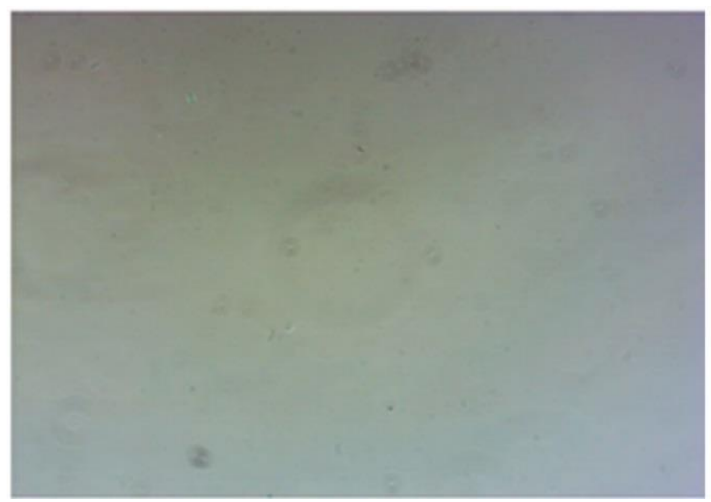

Figura 11: Imagem representativa do poço de células (NCTC clone L929) incubadas com a substância de referência Zdec.

A eficácia da análise também pôde ser verificada visualmente pela aparência das imagens nos poços das placas usadas, contendo células tratadas com diferentes diluições do extrato de cada amostra. Onde ocorreu maior morte celular (controle positivo em concentração de extrato 100\%), a imagem não permitiu a visualização das células, indicando que não houve precipitação do MTT (Figura 11). Por outro lado, para os micropoços nos quais as células permaneceram vivas, o meio apresentou um aspecto rugoso, indicando ausência de reatividade na presença do fosfato tricálcico. Desta forma, é possível afirmar que o fosfato de cálcio, utilizado no ensaio in vitro de citotoxicidade, demonstrou biocompatibilidade, não apresentando efeito tóxico. Tal resultado é indicativo de que o material seja adequado para aplicações biomédicas [38].

$\mathrm{Na}$ análise quantitativa da apatita (Equação 3), a viabililidade apresentou valor de $100 \%$, enquanto a amostra de referência, Zdec, ficou com $0,012 \%$.

Segundo os resultados, a amostra de fosfato tricálcico- $\beta$ é atóxica, uma vez que, nas condições laboratoriais testadas, apresentou valor de viabilidade celular maior do que $90 \%$. A amostra Zdec, por sua vez, apresentou viabilidade menor do que 50\%, o que caracteriza o material como tóxico [3].

Tal qual esta pesquisa, vários autores mencionam a biocompatibilidade das biocerâmicas de fosfato de cálcio. De acordo com ZOU [18], o TCP- $\beta$ sintetizado por precipitação em solução aquosa e calcinado a 900 ${ }^{\circ} \mathrm{C}$, durante 3 horas, apresentou resultados satisfatórios de biocompatibilidade. GENG [37], utilizando uma linhagem celular semelhante a osteoblastos (MG63), mostrou que o magnésio revestido com TCP- $\beta$ é não tóxico e biocompatível. ALCAIDE et al. [39], ao analisarem uma mistura de hidroxiapatita (27\%) e TCP- 
$\beta /$ agarose (73\%), utilizando uma linhagem celular de fibroblastos e osteoblastos, constataram que o biomaterial é biocompativel para utilização em processos de reparação óssea. CHEN et al. [40] verificaram a citotoxicidade em três fases de fosfato de cálcio: TCP- $\beta$ puro, bifásico (hidroxiapatita/TCP- $\beta$ ) e hidroxiapatita pura. Como não ocorreram alterações significativas dos tratamentos em relação ao controle, no teste MTT, a não toxicidade das amostras foi novamente comprovada.

\section{CONCLUSÕES}

As caracterizações de difração de raios X, espectroscopia de infravermelho e microscopia eletrônica de varredura com espectroscopia de raios $\mathrm{X}$ por dispersão de energia comprovaram que a síntese adotada, via reação em estado sólido, levou à formação de um material homogêneo, tendo como fase cristalina o fosfato tricálcico- $\beta$.

Através do BET, o material sintetizado foi caracterizado como nanométrico. Após calcinação a 1000 ${ }^{\circ} \mathrm{C}$ das peças conformadas, as micrografias mostraram que a amostra cerâmica assumiu um caráter mais micrométrico, em função dos fenômenos físicos usualmente observados em temperaturas elevadas para essa classe de materiais, como crescimento de partículas e densificação.

Os resultados de citotoxicidade in vitro indicaram que a exposição das células à amostra de TCP- $\beta$, nas concentrações avaliadas, não apresentaram alterações celulares morfológicas, como também não inibiram o crescimento celular.

Por fim, todas as caracterizações realizadas demonstraram que a reação em fase sólida de hidróxido de cálcio e hidrogeno fosfato de cálcio permite a obtenção de TCP- $\beta$ monofásico, desde que seja empregada a combinação adequada dos parâmetros de síntese. O material obtido não apresenta toxicidade, é biocompatível e se mostra um forte candidato para aplicações biomédicas.

\section{AGRADECIMENTOS}

Os autores agradecem à Central Analítica, aos laboratórios de Raios X e de Química Orgânica e Inorgânica da Universidade Federal do Ceará e ao laboratório Biotechcell® da Universidade Estadual do Ceará. Agradecem também à Coordenação de Aperfeiçoamento de Pessoal de Nível Superior (CAPES) pelo fomento à pesquisa.

\section{BIBLIOGRAFIA}

[1] HENKEL, J., WOODRUFF, M. A., EPARI, D. R., et al., "Bone Regeneration Based on Tissue Engineering Conceptions - A 21st Century Perspective”, Bone Research, v. 3, pp. 216 - 248, 2013.

[2] GUTIERRES, M., LOPES, M. A., HUSSAIN, N. S., et al., "Substitutos Ósseos Conceitos Gerais e Estado Actual”, Arquivos de Medicina, v. 19, n. 4, pp. 1 - 10, 2006.

[3] INTERNATIONAL ORGANIZATION FOR STANDARDIZATION, "Biological evaluation of medical devices". Part 5: Tests for cytotoxicity: in vitro methods", 3st ed, ISO 10993-5, 2009.

[4] PITHON, M. M., SANTOS, R. L., RUEllaS, A. C. O., et al., "Citotoxicidade in vitro de elásticos ortodônticos: comparação entre duas metodologias”, Revista Saúde.Com, v. 4, pp. 19 - 26, 2008.

[5] WILLIANS, D. F., “On the mechanisms of biocompatibility”, Biomaterials, v. 29, issue. 20, pp. 2941 2953, 2008.

[6] GHANI, S. A., MASUDI, S. M., OMAR, N., "A cytotoxic evaluation of 7th generation dentin bonding agent on human pulp cells", Journal of Dentomaxillofacial Science, 2016.

[7] NEILSON, L., MANKUS, C., THORNE, D., et al., "Development of an in vitro cytotoxicity model for aerosol exposure using 3D reconstructed human airway tissue; application for assessment of e-cigarette aerosol", Toxicology in Vitro, v. 29, n. 7, pp. 1952-1962, 2015.

[8] CORREA, D., AlMirall, A., CARRODEGUAS, R. G., et al., " $\alpha$-Tricalcium phosphate cements modified with $\beta$-dicalcium silicate and tricalcium aluminate: Physicochemical characterization, in vitro bioactivity and cytotoxicity”, Journal of Biomedical Materials Research Part B: Applied Biomaterials, v. 103, n. 1, pp. 72-83, 2015. 
[9] POGGIO, C., ARCIOLA, C. R., BELTRAMI, R., et al., "Cytocompatibility and Antibacterial Properties of Capping Materials", Scientific World Journal, 10p., 2014.

[10] RIETVELD, H. M., “A profile refinement method for nuclear and magnetic structures”, Journal Applied Crystallography, v. 2, pp. 65-71, 1969.

[11] BLEICHER, L., SASAKI, J. M., PAIVA SANTOS, C. O., "Development of a graphical interface for the Rietveld refinement program DBWS", Journal Applied Crystallography, v. 33, 2000.

[12] INTERNATIONAL ORGANIZATION FOR STANDARDIZATION, "Biological evaluation of medical devices". Part 12: Sample preparation and reference materials, 4 ed, ISO 10993-12, 2012.

[13] HAYEK, E., NEWESLEY, H., "Inorganic Syntheses", New York: McGraw Hill, v. 7, pp. 63 - 65, 1963.

[14] AZEVEDO, A. G. S., STRECKER, K., "Avaliação da influência da razão $\mathrm{Ca} / \mathrm{P}$ nos valores de cristalinidade e crescimento de cristais durante a sinterização de pós de hidroxiapatita", Revista eletrônica de materiais e processos (ufcg), v. 9, p. 125 - 129, 2014.

[15] BATISTA, T. S. A., SANTOS-FILHO, J. B., "Calcita, Hidroxiapatita e B-Fosfato Tricálcio como absorventes de ultravioleta", Aracaju: Editora IFS, 1 ed., v.1, 2016.

[16] DUARTE, E. B., "Processamento de Hidroxiapatita por Microondas: Síntese de Pós e Sinterização de Peças"., Dissertação de M.Sc., Universidade Federal do Ceará, Fortaleza, 2009.

[17] OPRITA, E. I., MOLDOVAN, L., CRACIUNESCU, O., et al., "A bioactive collagen- $\beta$ tricalcium phosphate scaffold for tissue engineering", Central European Journal of Biology, v. 2, n.1, pp. 61-72, 2006.

[18] ZOU, C., WENG, W., DENG, X., et al., "Preparation and characterization of porous $\beta$-tricalcium phosphate/collagen composites with an integrated structure", Biomaterials, v. 26, n. 26, pp. $5276-5284$, 2005.

[19] ARAÚJO, T. S., "Produção de hidroxapatita pura e dopada para aplicação em biosensores", Dissertação de M.Sc., Departamento de Física, Universidade Federal de Sergipe, São Cristóvão, Brasil, 2006.

[20] DUARTE, E. B., "Produção de Nanocompósitos de Celulose Bacteriana e Hidroxiapatita como Rota para Valorização de Resíduos Agroindustriais", Tese de D.Sc., Universidade Federal do Ceará, Fortaleza, 2014.

[21] LANDI, E., TAMPIERI, A., CELOTTI, G., SPRIO, S., "Densification Behaviour and Mechanisms of Synthetic Hydroxyapatites", Journal of the European Ceramic Society, v. 20, pp. 2377 - 2387, 2000.

[22] RAYNAUD, S., CHAMPION, E., ASSOLANT, D. B., et al., "Calcium phosphate apatites with variable $\mathrm{Ca} / \mathrm{P}$ atomic ratio I. Synthesis, characterisation and thermal stability of powders", Biomaterials, v. 23, n. 4, pp. 1065-1072, 2002.

[23] BUI, V. X., Élaboration de biomatériaux verres-substances actives (zolédronate-chitosane): caractérisations physico-chimiques: expérimentations "in vitro", These (Docteur, Ecole doctorale Sciences de la Matière), Rennes , França, Université de Rennes, UR, 2011.

[24] KUNDU, B., LEMOS, A., SOUNDRAPANDIAN, C., et al., "Development of porous HAP and - $\beta$ TCP scaffolds by starch consolidation with foaming method and drug-chitosan bilayered scaffold based drug delivery system", Journal of Materials Science: Materials in Medicine, v. 21, n. 11, pp. 2955-2969, 2010.

[25] REHMAN, M. U., JAWAID, P., KONDO, T., "Dual Effects of Nanoparticles on Radiation Therapy:

As Radiosensitizers and Radioprotectors”, Radiation Environment and Medicine, v. 5, n.1, pp. 40-45, 2016.

[26] BOVERHOF, D. R., BRAMANTE, C. M., BUTALA, J. H., et al., "Comparative assessment of nanomaterial definitions and safety evaluation considerations", Regulatory Toxicology and Pharmacology, v. 73, pp. 137 - 150, 2015.

[27] BUSQUETS, R., "Emerging Nanotechnologies in Food Science". Elsevier. Micro \& Nano Technologies Series, p.1, 2017.

[28] PAUW, B. R., KÄSTNER, C., THÜNEMANN, A. F., "Nanoparticle Size Distribution Quantification: Results of a SAXS Inter-Laboratory Comparison", ARXIV: 1702.03902 (physics.data-an), 2017.

[29] RUNOWSKI, M., LIS, S., "Nanocrystalline rare earth fluorides doped with Pr3+ ions", Journal of rare earths, v. 34, n.8, 2016.

[30] LIU, C., HE, H.,"Developments and Applications of Calcium Phosphate Bone Cements", Springer series in biomaterials science and engineering, v. 9, 2017.

[31] RENAUDIN, G., GOMES, S., NEDELEC, J. M., "First-Row Transition Metal Doping in Calcium 
Phosphate Bioceramics: A Detailed Crystallographic Study”, Materials, v. 10, n. 1 p. 92, 2017.

[32] HASSAN, M. N., MAHMOUD, M. M., EL-FATTAH, A. A., et al., "Microwave-assisted preparation of Nano-hydroxyapatite for bone substitutes", Ceramics International, v.42, pp. 3725-3744, 2016.

[33] BUTLER, D. H., GROSS, R. S., "Formation of Biphasic Hydroxylapatite-Beta Magnesium Tricalcium Phosphate in Heat Treated Salmonid Vertebrae", Scientific Reports 7, Article number: 3610, 2017.

[34] TORRESA, P. M. C., ABRANTES, J. C. C., KAUSHALA, A., et al., "Influence of Mg-doping, calcium pyrophosphate impurities and cooling rate on the allotropic $\alpha \leftrightarrow \beta-$ tricalcium phosphate phase transformations", Journal of the European Ceramic Society, v. 36, pp. 817-827, 2016.

[35] ROGERO, S. O., LUGÃO, A.B., IKEDA, T. I., et al., "Teste in vitro de Citotoxicidade: Estudo Comparativo entre Duas Metodologias”, Materials Research, v. 6, pp. 317 - 320, 2003.

[36] DAGUANO, J. K. M. F., SANTOS, C., ROGERO, S. O., “Avaliação da Citotoxicidade de Biocerâmicas Desenvolvidas para uso em Sistemas de Implantes”, Matéria (R.J.), v. 12, n. 1, pp. 134 - 139, 2007.

[37] GENG, F., TAN, L. L., JIN, X. X., et al., "The preparation, cytocompatibility, and in vitro biodegradation study of pure $\beta$-TCP on magnesium", Journal of Materials Science: Materials in Medicine, v. 20, n. 5, pp. $1149-1157,2009$.

[38] KIM, M., KYOUNG-NAM, K., LEE, Y. K., et al., "Cytotoxicity test of dentin bonding agents using millipore filters as dentin substitutes in a dentin barrier test”, Clinical Oral Investigations, v. 17, pp. 14891496, 2013.

[39] AlCAIDE, M., SERRANO, M. C., PAGANI, R., et al., "L929 Fibroblast and Saos-2 Osteoblast Response to Hydroxyapatite- $\beta$-TCP/agarose Biomaterial", Journal of Biomedical Materials Research, v. 89A, n. 2, pp. $539-549,2009$.

[40] CHEN, Y., WANG, J., ZHU, X. D., et al., "Enhanced Effect of $\beta$-tricalcium Phosphate Phase on Neovascularization of Porous Calcium Phosphate Ceramics: In vitro and in vivo evidence", Acta Biomaterialia, v. 11, pp. 435 - 448, 2015. 